\title{
A SIMULATION-BASED PLANNING SYSTEM FOR WIND TURBINE CONSTRUCTION
}

\author{
Dina Atef \\ Hesham Osman \\ Moheeb Ibrahim \\ Department of Structural Engineering \\ Cairo University \\ Giza, EGYPT
}

\author{
Khaled Nassar \\ Department of Construction Engineering \\ American University in Cairo \\ Cairo, EGYPT
}

\begin{abstract}
Wind turbine construction is a challenging undertaking due to the need to lift heavy loads to high locations in conditions of high and variable wind speeds. These conditions create great risks to contractors during the turbine assembly process. This paper presents a simulation-based system to aid in the construction planning of wind turbines. The system is composed of three main components; 1) A wind speed forecasting module based on artificial neural networks, 2) A series of discrete event simulation models that act as a test bed for different turbine construction methods and resource utilizations, and 3) A rule-based system that relates prevalent wind speed to the impact on lifting activity durations. Actual wind speed data from the Zafarana wind farm in Egypt is used and turbine construction productivity and resource utilization is compared for two common turbine construction methods.
\end{abstract}

\section{INTRODUCTION}

By the end of 2009, the nameplate capacity for worldwide production of wind power using wind turbine generators reached almost 157.9 gigawatts $(\mathrm{GW})$. In $200938.3 \mathrm{GW}$ were added. The wind energy production capacity grew by $31 \%$, the highest rate since 2001. Predictions are that $54 \mathrm{GW}$ will be added in 2010 (WWEA, 2009). This ambitious growth requires a significant ramp-up in all links of the wind turbine supply chain. Wind turbine construction is one of the most critical yet under-investigated steps in the supply chain of wind turbines. Wind turbine construction is a repetitive construction process that mainly involves lifting large prefabricated components to large heights in high wind speed conditions. Thus, contractors are faced with challenging work environments that impact the time, cost and safety of construction operations. Turbine construction cost can sometimes constitute a significant component of the total lifecycle cost. Construction cost is dependent on several variables that include the height of the wind turbine, the total number of wind turbines to be installed, and the number of wind turbines installed per crane mobilization. A recent study in the economies of wind turbine construction have estimated the installation cost to range from $\$ 40,000-\$ 350,000$ per tower depending on the aforementioned variables (Wisconsin Energy Center, 2007). The unique nature of wind farm construction coupled with high construction costs warrant the development of specific construction planning tools that can be used to plan construction operations at the strategic and tactical levels. This paper is one step towards this objective.

\subsection{Challenges in wind farm construction}

Research in wind energy has given little mention of the challenges facing the construction of wind turbines. From a life cycle perspective, most of the literature has focused on the planning, design, and operation phases of wind turbines. Wind turbine construction is a critical link in the supply chain of wind 
energy, yet little is documented about the challenges facing contractors during the construction of wind farms. The following lists some of these challenges:

\subsubsection{Impact of wind during construction}

Wind farm sites are typically selected in areas of high wind speeds. High wind speeds pose specific problems during the erection of wind turbines (Carns and Bender, 2008). From a contractor's perspective, high wind speeds during heavy lifts pose three distinct problems:

- Safety: Could lead to crane overturning, especially during times of fluctuating wind speed and the occurrence of wind gusts.

- Time: During high wind speeds, construction may be interrupted and lifts in progress can be aborted leading to delays in the construction schedule

- Cost: Postponing a lift or aborting a lift that is in progress translates to idle time for the lifting equipment and supporting crews. This leads to under-utilization of the lifting equipment (which tends to be relatively costly) and an overall increase in construction costs.

The uncertainty associated with wind speed forecasts coupled with the uncertainty in construction processes poses significant challenges for contractors to adequately plan their lifts.

\subsubsection{Lack in formal understanding of wind speed impact}

There is a lack in a formal well-documented understanding of how wind impacts hoisted objects. Typically most safety standards require lifting operations to stop after a specific wind speed OSHA (2010). These requirements have not been substantiated by any formal scientific studies. Potential for crane overturning in windy conditions depends on the shape of hoisted objects, crane type, and severity of wind gusts. There have been no formal studies on the actual effect of wind speed on potential for crane overturning.

Before safety thresholds have been met and lifting operation must be stopped, wind speeds have a direct impact on the time required to complete a lift. Generally speaking, lift times are inversely proportional to wind speeds. Unfortunately, there is a lack in understanding of this relationship. Wind turbine contractors lack accurate tools to quantify the direct time delays associated with lifting during high wind speeds.

\subsubsection{Increase in turbine size}

Over the last 20 years wind turbine size has grown exponentially. This growth is placing increasing pressures on contractors to lift larger, heavier components to higher locations. This dynamic poses the following challenges to contractors:

- Heavier lifts at higher locations translate into cranes of larger capacities, or the need to use multiple cranes for a single lift. In turn, this translates into higher rental costs and larger losses in case of lift cancellation.

- Higher lifts translate into higher wind speeds as the wind shear effect decreases with height above ground surface. This leads to heightened safety concerns and an increased possibility of lift cancellation.

The components of a wind turbine are typically prefabricated and transported to site for assembly. Typical components that are assembled on site include the sections of the tower, blades and nacelle. This leads to the following challenges to contractors: 


\section{Atef, Osman, Ibrahim and Nassar}

- Transportation of these components to remote wind farm locations will require the construction of new roads or the widening and strengthening of existing roads and bridges. Within the wind farm site, temporary access roads that were typically constructed for maintenance equipment now need to accommodate larger transport trucks during construction.

- With increasing turbine size, the blades and nacelle are becoming larger and heavier. There is no opportunity to assemble these components on site and reduce the size of lifts.

\subsubsection{Wind farm locations}

Wind farms are typically constructed in undeveloped rural areas with challenging topography. The lack of a paved road network leading to the site and within the site itself pose significant challenges to the planning of wind farm construction. Contractors need to answer the following questions:

- What sequence should be followed during wind turbine erection?

- What cranes are most cost effective to use in a particular topography?

- When is it more cost effective and safe to use multiple cranes for a single lift versus a large crane?

\subsection{Objectives}

The wider objectives of this research are the development of a set of tailored construction planning tools for the wind turbine construction industry. For wind farm contractors, these tools will result in better management of construction risks, more realistic planning, more cost-effective utilization of construction resources, safer work environments, and shortened project durations. For wind farm developers these benefits will simply translate into cheaper wind turbines constructed in shorter durations.

This paper presents a strategic construction planning system for wind turbine construction. The system aims to integrate wind speed forecasting models with discrete event construction simulation models of wind turbine construction for the accurate planning of construction activities.

\section{WIND TURBINE CONSTRUCTION METHODS}

Wind turbines usually consist of 4 main components. The turbine tower ( 3 or 4 tubular steel sections), fully assembled nacelle (including gearbox, generator, yaw mechanism, mechanical break, converter, and transformer), hub, and rotor blades.

Wind turbines are constructed by lifting and subsequently assembling the aforementioned components in sequence. Tower sections are initially lifted in a horizontal position, then tilted upright, and assembled to the previously erected section. The steel sections are bolted together from inside the tower. Once the steel sections are bolted, nacelle, hub, and rotor blades are lifted and erected (Carns and Bender, 2008).

The aforementioned construction sequence can be achieved via different construction methods. These methods can be classified according to: 1) Turbine assembly strategy and; 2) Resource utilization approach. The assembly approach describes the assembly sequence and location of the hub and blades. The resource utilization approach describes the method of utilizing the most critical resource during turbine erection; the lifting cranes..

Generally speaking there are two common turbine assembly strategies:

1. Ground-based blade assembly. This involves assembling the blades and hub on the ground and lifting these components after tower sections and hub are in place.

2. Tower-based blade assembly: This involves lifting tower sections, nacelle, hub, and blades each separately. The blades are attached to the hub atop of the tower. 
With regards to resource utilization, two approaches are common:

1. Using a large capacity crawler crane

2. Using a small capacity wheel-mounted crane for the base and center tower sections and a larger capacity crawler crane for the upper tower sections and nacelle

Each alternative construction method, is a different combination of the turbine assembly strategies with the resource utilization approaches, producing four different construction methods listed Table 1.

Table 1: Alternative construction methods of wind turbines

\begin{tabular}{|c|l|}
\hline $\begin{array}{c}\text { Construction } \\
\text { Method }\end{array}$ & \multicolumn{1}{|c|}{ Description } \\
\hline Method $\mathrm{A}(1)$ & Application of $1^{\text {st }}$ turbine assembly Strategy , and $1^{\text {st }}$ resource utilization approach \\
\hline Method $\mathrm{A}(2)$ & Application of $1^{\text {st }}$ turbine assembly Strategy, and $2^{\text {nd }}$ resource utilization approach \\
\hline Method $\mathrm{B}(1)$ & Application of $2^{\text {nd }}$ turbine assembly Strategy, and $1^{\text {st }}$ resource utilization approach \\
\hline Method $\mathrm{B}(2)$ & Application of $2^{\text {nd }}$ turbine assembly Strategy, and $2^{\text {nd }}$ resource utilization approach \\
\hline
\end{tabular}

\section{SYSTEM OVERVIEW}

The developed system is a simulation-based strategic planning system, used to investigate the interaction between uncertain physical phenomena (wind speed) and the construction process of wind turbines. In this paper, the developed system will be used to evaluate the efficiency of various construction methods in variable wind speed conditions. The system consists of three main modules as shown in Figure 1;

1) Wind Forecasting Module, 2) Construction Simulation Module, and 3) Wind Speed Rule-Base. The Wind Forecasting Module utilizes Artificial Neural Networks to predict wind speed during the construction phase based on historical wind records. Predictions are long-term forecasts throughout the expected duration of construction. The Construction Simulation Module contains a collection of discrete event simulation models for the construction process considering various turbine assembly strategies and resource utilizations. The Wind Speed Rule-Base is a collection of If-Then rules that govern how various construction activities are impacted by wind. The impact is through either an increase in activity duration or the total cancellation of an activity due to safety concerns.

The inputs to the Construction Simulation Module are: alternative construction methods, the output wind speed of the Forecasting Module, and the Rule-Base system that controls wind speed impact on activities' duration. The outputs of the simulation module are: the time and cost of each method, from which the most suitable method is selected. 


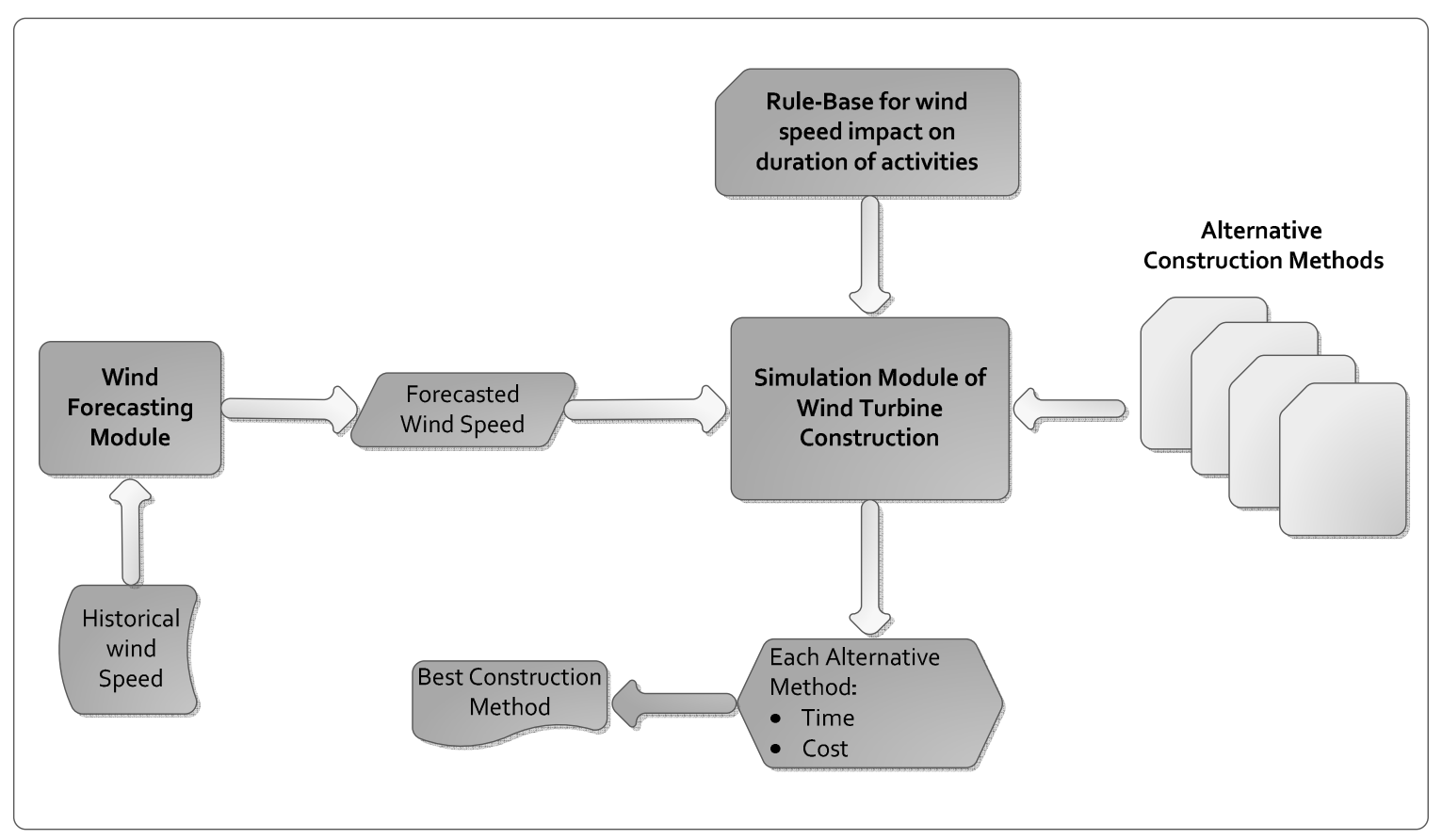

Figure 1: Framework of the wind turbine construction planning system

\subsection{Long-term wind speed forecasting module}

The Wind Forecasting Module is capable of predicting the average hourly wind speed for a particular planning window. Wind speed forecasting models have utilized several modeling paradigms that include multiple regression (Ewing et al. 2006; Riahy and Abedi 2008), and (Palomares-Salas et al. 2010) artificial neural networks (Zhang and Kline 2007) and (Mohandes and Rehman 1998). Recent studies have shown that Neural Networks produce satisfactory results in long term prediction of average hourly wind speed (Kalogirou and Michaelides 2004).

A neural network is trained based on actual wind speed data from the Zafaarana area, Gulf El Suez, Egypt. The area is selected as it is currently the largest wind farm site in the middle east with plans to build Egypt's first 250MW private wind power plant. Wind speed records for the years from 1992 to 2001 were used in training and testing the network, while the records for the year 2002 were used for validating the network. Different Neural Network structures were tested tried out till the structure with the best accuracy is selected. The correlation coefficient is taken as an indication for the accuracy. The correlation coefficient of the selected structure, after training and testing, is 0.898 . The selected network structure, as shown in Figure 2, consists of 5 slabs; 1 input slab, 3 hidden slabs, and 1 output slab (Kalogirou and Michaelides 2004). 


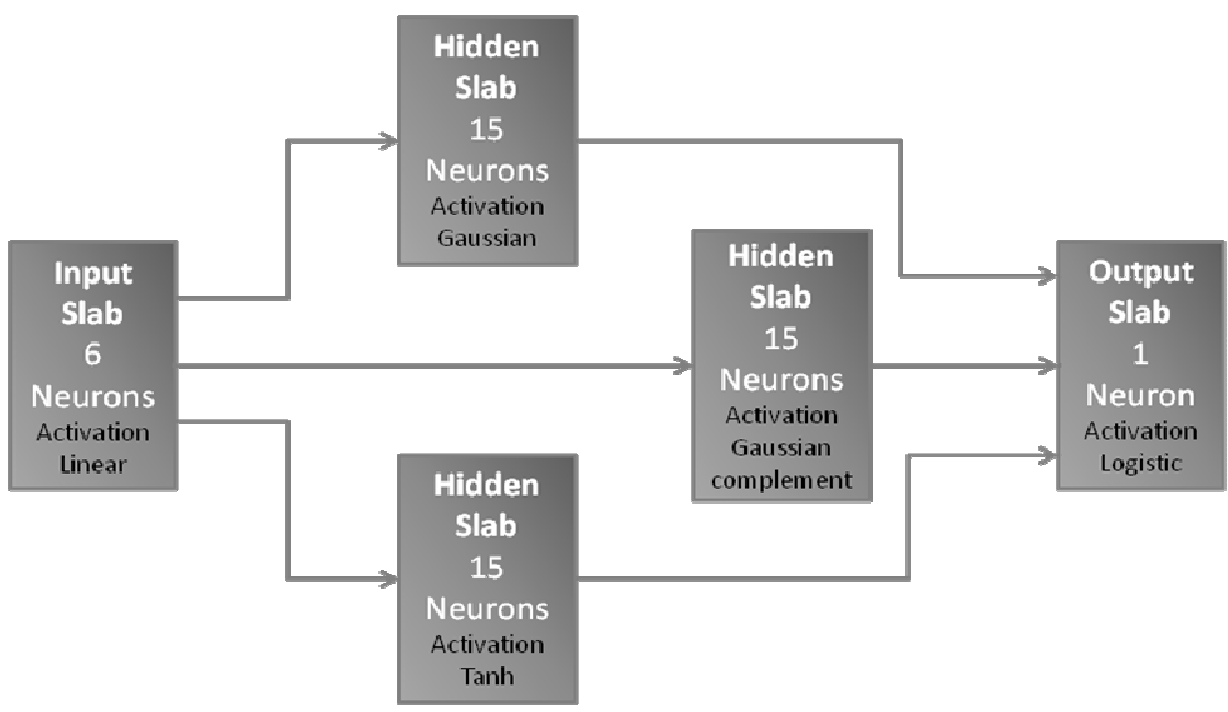

Figure 2: Structure of Neural Network for wind speed forecasting

The neural network structure is a feed-forward structure, using back-propagation algorithm. The input slab consists of six neurons; month, day, hour , and three consequent years of average hourly wind speed records. The output slab consists of one neuron; the average hourly wind speed of the next year. The hidden slabs, each consists of 15 neurons. The network is trained on data from year 1992 to 2001. The training procedure involved incremental learning in 3-year steps. For example year 1995 is taken as an output where the input wind speed of the same month, day, and hour of three previous years (1992-1994).

The network is then re-trained with 1996 as an output , and (1993-1995) as input and on. The year 2002 was left for validation of the network. A similar methodology was adopted by (Kalogirou and Michaelides 2004).

The actual observations versus the model forecasting is plotted for the average hourly wind speed for a day in July 2002 (Figure 3). The difference between the actual wind speed and the network forecasted wind speed, usually ranges from (0.1-2) $\mathrm{m} / \mathrm{s}$. This difference sometimes rises up to $4 \mathrm{~m} / \mathrm{s}$, due a sudden drop in the actual wind speed of the year 2002. This level of prediction accuracy is deemed satisfactory for use in evaluating the impact on construction activities as shown in the following section.

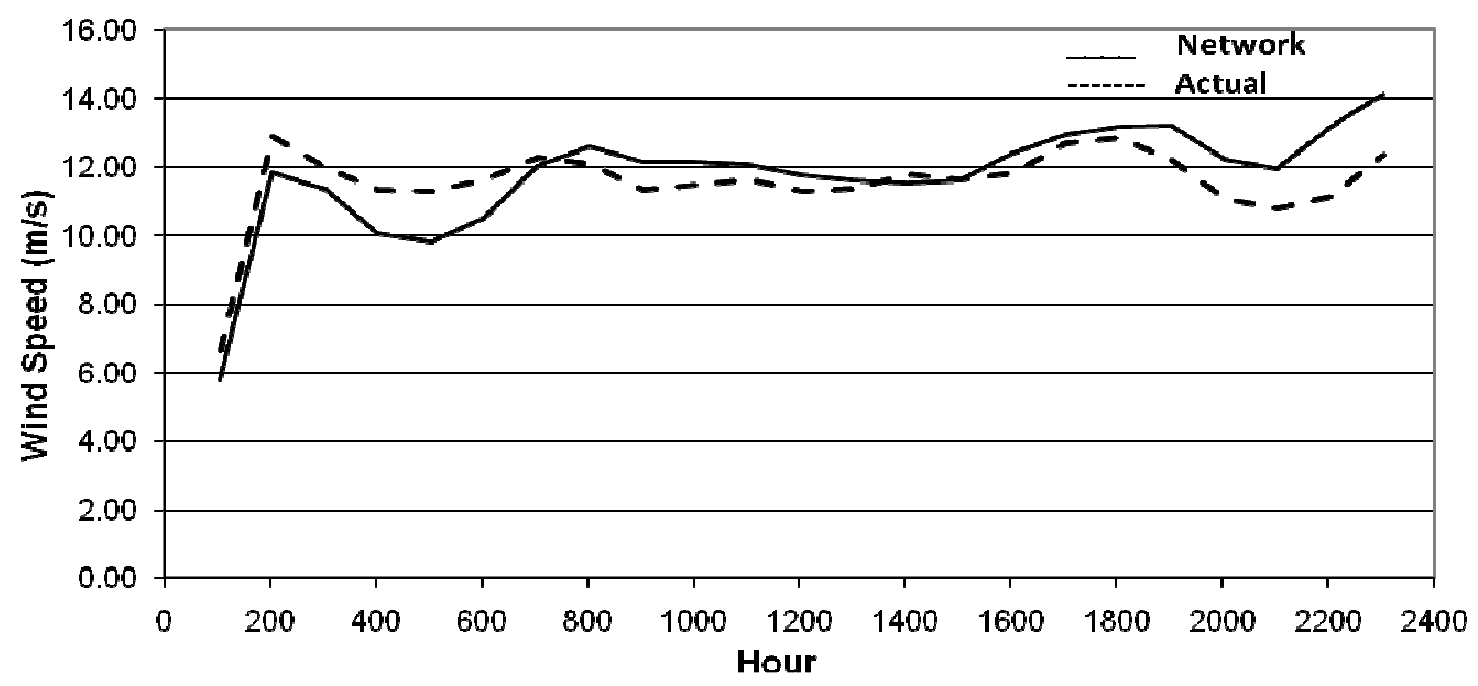

Figure 3: Actual observations versus network forecasting for the average hourly wind speed of one day 


\subsection{Discrete event simulation module}

A series of discrete event simulation models are developed to represent the wind turbine construction methods described in the previous section. The models utilize the STOBOSCOPE simulation environment (Martinez 1996). Methods $\mathrm{A}(1)$ and $\mathrm{B}(1)$, listed in Table 1, are coded and developed using the STROBOSCOPE programming language. The sequence and resource interaction of wind turbine construction is modeled and graphically represented using STROBOSCOPE GUI (Figure 3). The main components of the two models, the construction activities, and utilized resources are listed in Table 2. Preliminary assumptions of construction resources, based on observations of turbine construction projects, included:

- One main crane,

- One secondary crane for aiding the main crane in tilting the wind turbine parts,

- One crew for bolting steel sections together,

- One crew for bolting the hub and blades,

- Triangular distribution of the activities' duration,

- 1Shift/day; 8 working hours/day,

- 5 working days/week.

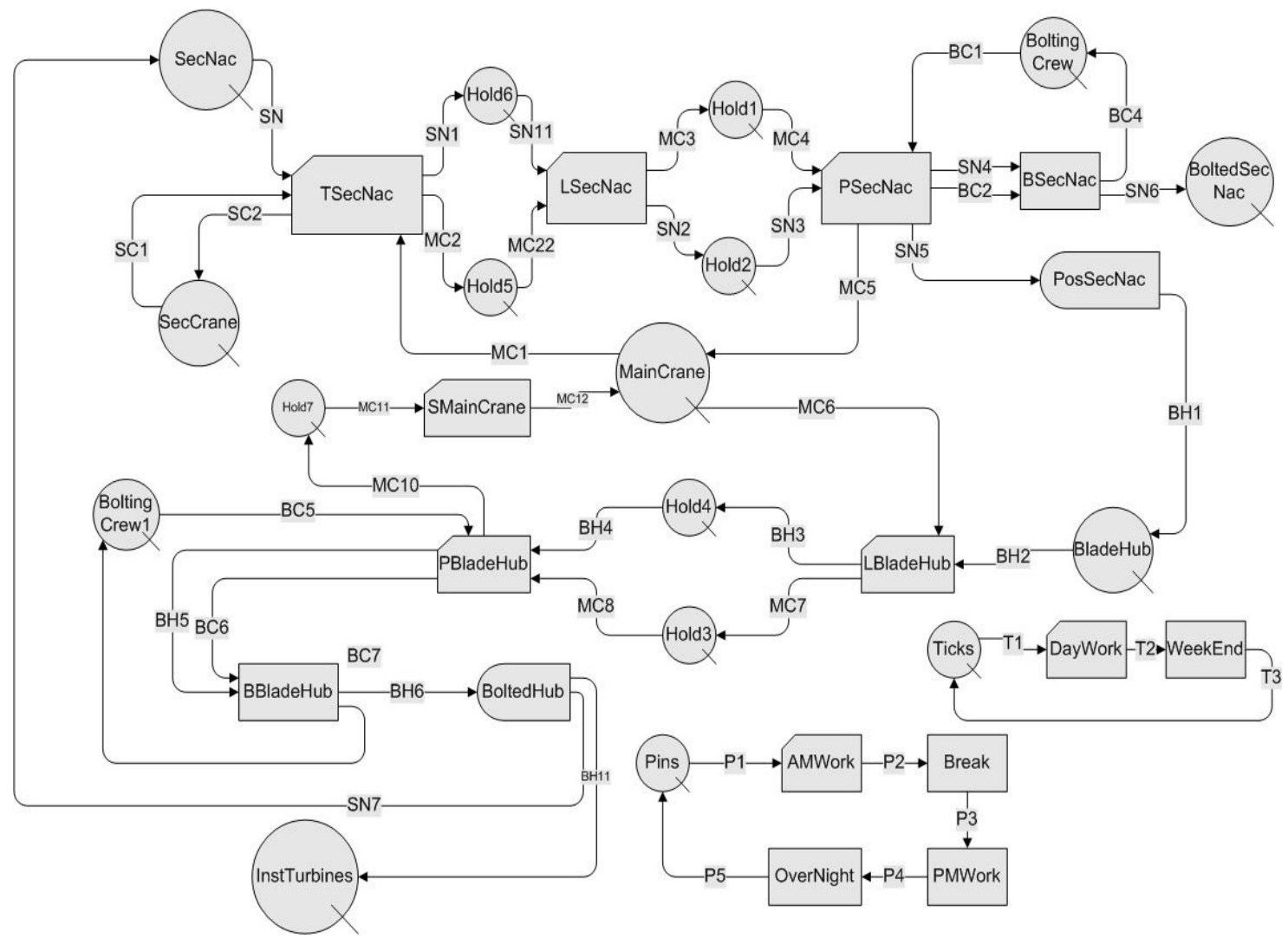

Figure 4: Graphical representation of the simulation model "Model B(1)" 
For Model A(1), the construction sequence is as follows:

1. The first tubular section is tilted using the main crane with the aid of the secondary crane.

2. Then, the section is lifted using the main crane and positioned above the previously constructed foundation.

3. After erecting the 1 st section, the $2^{\text {nd }}$ section will be tilted, lifted, and positioned on the previously erected section, and so forth with the 3rd section and the nacelle.

4. Once the section is positioned, the bolting crew starts bolting the positioned section with the previously erected one.

5. After the secondary crane finishes aiding the main crane in lifting the nacelle, it will be utilized in assembling the blades with the hub on ground.

6. Then, the hub with the blades will be tilted, lifted, and positioned, then bolted to the nacelle.

For Model $\mathrm{B}(1)$, the construction sequence is almost identical as model $\mathrm{A}(1)$. The main difference is after positioning the nacelle above the 3 rd section. The hub and blades will be lifted separately using the main crane and bolted to the nacelle.

Variation in activity duration due to the impact of wind on the construction process is captured via a basic rule-base system. The rule-base is developed based on expert judgment. The rule-base is in the form of a series of if-then rules that take into consideration: 1) The value of the wind speed, 2) The type of lifting activity, and 3) The height of the lifted component. An example of a simple rule is:

- IF wind speed $>14 \mathrm{~m} / \mathrm{s}$ THEN cancel the lifting activity

- IF $8<$ wind speed $<14 \mathrm{~m} / \mathrm{s}$ and center section is being installed THEN increase the duration of the activity with a factor of 1.2

The two models are run, using the average hourly wind speed of each month of the year as an input. For each month, four simulation runs are undertaken. For each month/each model, the total number of wind turbines installed, the utilization factor of the main crane, and the utilization factor of the secondary crane are recorded. 
Table 2: Details of the two developed simulation models

\begin{tabular}{|c|c|c|c|c|c|}
\hline $\begin{array}{l}\text { Model } \\
\text { compo- } \\
\text { nents }\end{array}$ & Name & Description & Resources & $\begin{array}{l}\text { Model } \\
\text { A(1) }\end{array}$ & $\begin{array}{c}\text { Model } \\
\mathrm{B}(1)\end{array}$ \\
\hline \multirow{6}{*}{ Queues } & $\mathrm{SecNac}$ & $\begin{array}{l}\text { Contains steel sections and } \\
\text { nacelle }\end{array}$ & Wind turbine parts & $\mathrm{E}$ & $\mathrm{E}$ \\
\hline & MainCrane & Contains main crane & Main Crane & $\mathrm{E}$ & $E$ \\
\hline & SecCrane & Contains secondary crane & Secondary Crane & $\mathrm{E}$ & $\mathrm{E}$ \\
\hline & BoltingCrew & $\begin{array}{l}\text { Contains bolting crews for } \\
\text { bolting sections together }\end{array}$ & Bolting Crews & $\mathrm{E}$ & $\mathrm{E}$ \\
\hline & BoltingCrew1 & $\begin{array}{l}\text { Contains bolting crews } \\
\text { For bolting blades \& hub }\end{array}$ & Bolting Crews & $\mathrm{E}$ & $\mathrm{E}$ \\
\hline & BladeHub & $\begin{array}{l}\text { Contains the hub and the } 3 \\
\text { blades }\end{array}$ & Wind Turbine Parts & $\mathrm{E}$ & $\mathrm{E}$ \\
\hline \multirow{9}{*}{$\begin{array}{l}\text { Activi- } \\
\text { ties }\end{array}$} & TSecNac & $\begin{array}{l}\text { Tilting steel sections and } \\
\text { first lift of nacelle }\end{array}$ & $\begin{array}{l}\text { Main crane and second- } \\
\text { ary crane }\end{array}$ & $\mathrm{E}$ & $\mathrm{E}$ \\
\hline & LsecNac & $\begin{array}{l}\text { Lifting steel sections and } \\
\text { nacelle }\end{array}$ & Main crane & $\mathrm{E}$ & $\mathrm{E}$ \\
\hline & $\mathrm{PSecNac}$ & $\begin{array}{l}\text { Positioning steel sections or } \\
\text { nacelle on the previously } \\
\text { installed section }\end{array}$ & $\begin{array}{l}\text { Main crane and } \\
\text { bolting crew }\end{array}$ & $\mathrm{E}$ & $\mathrm{E}$ \\
\hline & $\mathrm{BSecNac}$ & $\begin{array}{l}\text { Bolting steel sections or } \\
\text { nacelle with the previously } \\
\text { installed section }\end{array}$ & Bolting Crews & $\mathrm{E}$ & $\mathrm{E}$ \\
\hline & ABladeHub & $\begin{array}{l}\text { Assembling blades with } \\
\text { hub on ground }\end{array}$ & $\begin{array}{l}\text { Secondary crane } \\
\text { and bolting crew }\end{array}$ & $\mathrm{E}$ & $\mathrm{DE}$ \\
\hline & LBladeHub & Lifting blades and hub & Main Crane & $\begin{array}{c}\mathrm{E} \\
\text { Assem } \\
\text { sem- } \\
\text { bled }\end{array}$ & $\begin{array}{c}\text { E } \\
\text { Each } \\
\text { sepa- } \\
\text { rately }\end{array}$ \\
\hline & PBladeHub & Positioning blades and hub & $\begin{array}{l}\text { Main crane and bolting } \\
\text { crew }\end{array}$ & $\begin{array}{c}\text { E } \\
\text { Assem } \\
\text { sem- } \\
\text { bled }\end{array}$ & $\begin{array}{c}\text { E } \\
\text { Each } \\
\text { sepa- } \\
\text { rately }\end{array}$ \\
\hline & BBladeHub & Bolting blades and hub & Bolting Crews & $\begin{array}{c}\mathrm{E} \\
\text { Assem } \\
\text { sem- } \\
\text { bled }\end{array}$ & $\begin{array}{l}\text { E } \\
\text { Each } \\
\text { sepa- } \\
\text { rately }\end{array}$ \\
\hline & SMainCrane & Setting up main crane & Main Crane & $\mathrm{E}$ & $\mathrm{E}$ \\
\hline
\end{tabular}

E : Existing

DE: Doesn't Exist 


\section{SIMULATION RESULTS}

A simulation of the construction process was undertaken for each month throughout the year to evaluate the impact of variations in wind speed on turbine assembly productivity. Figure 5 shows the monthly wind turbine construction productivity and hourly wind speed statistics throughout the year. The following observations were made after running the simulation model:

- Model A(1) consistently yields a larger wind turbine productivity throughout the year compared to Model $\mathrm{B}(1)$.

- Prevalent wind speed has a noted impact on wind turbine productivity. During the winter months (November - December) when wind speeds are low, wind turbine installation productivity is notably higher.

- The main crane was utilized in Model 1 with a utilization factor (0.92-0.95), while in Model 2 it was fully utilized. The effective operation of this resource is paramount to turbine productivity. Down time needs to be kept at minimum.

- The secondary crane was utilized in Model 1 with a utilization factor (0.4-0.44), while in Model 2 it was utilized with a utilization factor (0.05-0.07).

- There is only marginal difference (0-2 extra turbines/month) between the two models in the summer/fall months (May - October). Wind speeds during this time are high but fluctuations are not that common.

- There is a marked difference between the two models during the month of April. With Model A(1) 12 turbines can be installed while with model B(1) only 9 turbines can be installed. This $25 \%$ decrease in productivity can be explained by the large variations in average hourly wind speed (and instantaneous wind gusts) that are common in the area during spring.

From the previous observations, the following can be recommended:

- Model B(1) is not very suitable in conditions of low average wind speeds or high fluctuations in hourly wind speed. This can be explained by the larger impact of wind on blade assembly that occurs on top of the tower in Model B(1). In model A(1) blade assembly occurs on the ground and hence the impact of wind speed fluctuations is not as significant.

- During months of high wind speed with low fluctuations either model could be used, depending of course on the cost of resources utilized.

- The selection of a construction method should consider the wind speed conditions (both average speed and variations) in addition to resource costing. 

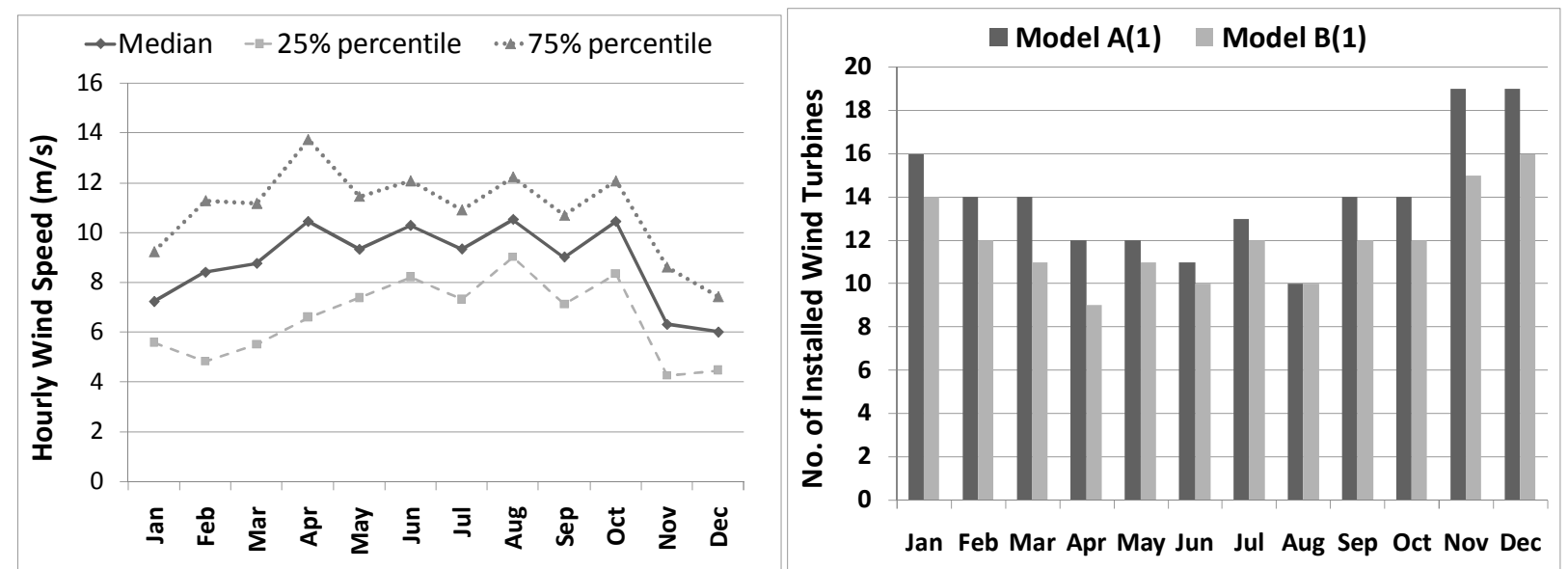

Figure 5: The number of wind turbines installed for each construction method and hourly wind speed in the Zaafarana area throughout the year.

\section{SUMMARY AND FUTURE WORK}

Wind turbine construction is inherently complex due to the effect of wind speed on the construction process. Various construction methods and resource utilizations are available for constructing wind turbines. This paper represents a simulation-based system that aids in planning the wind turbines construction. The system can be used to evaluate the suitability of various construction methods based on expected wind speeds. Results have shown that variations in wind turbine construction productivity depends both on wind speed and the construction method being used. These results highlight the usefulness of the developed tool to wind turbine contractors during the construction planning stage.

Work is underway to develop a stand-alone computer application that integrates the aforementioned modules. In addition more specialized turbine construction methods are being modeled as discrete event simulation models. The system will eventually be extended to include not only long-term wind speed forecasting but also short-term prediction that would be more useful as a management tool during construction.

\section{REFERENCES}

Ewing, B., J. Kruse, and J. Schroeder. 2006. Time series analysis of wind speed with time-varying turbulence. Environmetrics 2006; 17: 119-127

Carns, D.W., and W.J.Bender. 2010. Construction of a wind farm and case study. Central Washington University, Ellensburg, Washington. Available via <http://ascpro0.ascweb.org/> [accessed April 2, 2010].

Carns, D.W., and W.J., Bender. 2009. A case for wind farm construction. Wind Systems Magazine. September/October..

Kalogirou,S., and S. Michaelides. 2004. Time series prediction of wind speed. Nicosia, Cyprus. Available via <http://ktisis.cut.ac.cy/bitstream/10488/856/1/C65-Met.pdf> [accessed April 2, 2010].

Matinez,J.C. 1996.STROBOSCOPE State and resource based simulation of construction processes. $\mathrm{Ph}$. D.thesis, Department of Civil Engineering, Michigan University.

Mohandes, M.A., S. Rehman, and T.O. Halawani.1998. A Neural networks approach for wind speed predication. Renewable Energy.Vol.13, No.3, 345-354.

OSHA (2010) Mobile Crane Inspection Guidelines for OSHA Compliance Officers Appendix B - General Load Charts and Operational Considerations.. 
Palomares-Salas, J.C., J.J. G. de la Rosa, J.G. Ramiro, J.Melgar, A. Agüera and A. Moreno. 2010. Comparison of models for wind speed forecasting. Available Via < http: / /www.science.uva.nl> [accessed April 7,2010].

Riahy,G.H., and M. Abedi. 2008. Short term wind speed forecasting for wind turbine applications using linear prediction method. Renewable Energy 33 (2008), 35-41.

WWEA 2009. World Wind Energy Report. World Wind Energy Association.

Wisconsin Energy Center. 2007. The Self-Erecting Wind Turbine: Feasibility and Preliminary Design. Project summary developed by the Energy Center of Wisconsin for Xcel Energy. Available via <www.xcelenergy.com> [Accessed March 7, 2010]

Zhang, G.P., and D.M.Kline. 2007. Quarterly time-series forecasting with neural networks. IEEE Transactions on neural networks. Vol.18,No.6.

\section{AUTHOR BIOGRAPHIES}

DINA ATEF is a graduate student and research assistant with the Construction Management Group at the Department of Structural Engineering, Cairo University, Egypt. She graduated from the Department of Civil Engineering, Cairo University in 2008. Her email address is dinaatef.86 @hotmail.com>.

HESHAM OSMAN is an Assistant Professor with the Construction Management Group at the Department of Structural Engineering, Cairo University, Egypt. He is also an adjunct faculty at the Construction Management program at Nile University, Egypt. Prior to joining Cairo University, he was an Asset Management Specialist with AECOM Canada, a consulting firm in Toronto, where his work focused on the field of urban infrastructure asset management. His current research interests include urban infrastructure asset management and construction management of renewable energy projects. He received his Ph.D. from the University of Toronto in 2007. His email address is <hmosmanenileuniversity.edu.eg>.

MOHEEB IBRAHIM is a Professor with the Construction Management Group at the Department of Structural Engineering, Cairo University, Egypt. He teaches numerous construction engineering and management courses at the graduate and undergraduate levels and has supervised over $40 \mathrm{MSc}$ and PhD theses in this area throughout his academic career. His email address is <elsaid1204@yahoo.com>.

KHALED NASSAR is an Associate Professor at the American University in Cairo. Prior to joining AUC, he was on the faculty of Bradley University in Peoria, Illinois, the University System of Maryland, as well as the Chair of the Department of Architectural Engineering at the University of Sharjah, UAE. He has conducted research projects for the Illinois department of transportation and Caterpillar Inc, as well as NSF. He received a Ph.D. from Virginia Tech and worked for several years in the building industry. He has had several years of teaching experience in field of construction and architecture and has taught courses in computer applications and visualization ranging from CAD to simulation and multimedia. His email address is <knassareaucegypt. edu>. 